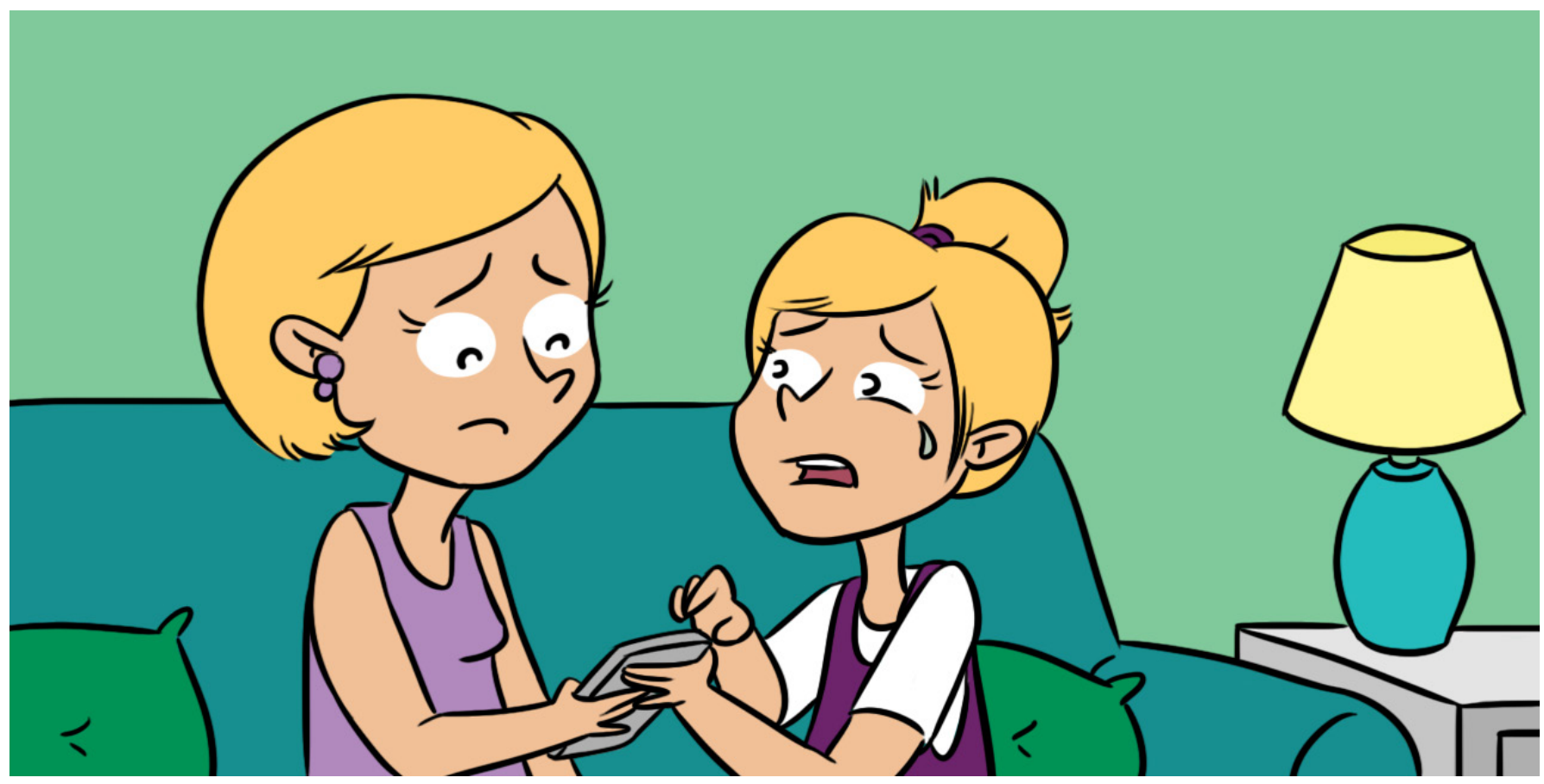

\title{
CYBERBULLYING AND SOCIAL CONNECTEDNESS
}

\section{Larisa T. McLoughlin* and Daniel F. Hermens}

Sunshine Coast Mind and Neuroscience Thompson Institute, University of the Sunshine Coast, Birtinya, QLD, Australia

\section{YOUNG REVIEWER:}

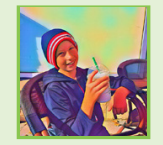

BROCK

AGE: 12
Do you have friends who have been bullied? What about cyberbullying bullying that happens online? How did bullying make your friends feel, and did they ask for help? Sadly, most of the times your friends will not ask for help when they have been cyberbullied. They may feel that no one can help, and so, they keep it to themselves. Not asking for help can be a big problem and cause a lot of worry and stress. Researchers know that feeling like they are connected to their friends can make young people feel happier. So, if a person is cyberbullied, then talking to friends and family can go a long way toward helping that person feel better. It can even help the bullying victim's mental health and can change the way that person copes with the worry and stress caused cyberbullying. This article talks about why being connected with friends and family is important for anyone being cyberbullied, and why parents, teachers, and schools should encourage kids to talk to them about cyberbullying. 


\section{CYBERBULLYING}

When one person does something nasty to another, a number of times, on purpose, with the intent to upset the other person.
MENTAL HEALTH

Good mental health is about being able to cope with day-to-day life stresses, to be able to work as best as you can, be involved in your community, and feel satisfied with life.

\section{WHAT IS CYBERBULLYING?}

Cyberbullying is when one person does something nasty to another, a number of times, on purpose, with the intent to upset the other person [1]. Cyberbullying can happen via social media (such as Facebook or Instagram), via an app (like Snapchat), or even via text messaging or emails. Cyberbullying has been a problem for a while, and roughly, one in four young people will experience it at some stage in their lives.

As cyberbullying is constantly changing due to new technology and new communication platforms, the way it is defined is also debated among researchers who study it. Traditionally, bullying involves a power imbalance between the victim and the bully. In other words, the bully is generally physically stronger than the victim. This may not always be the case in cyberbullying and being "stronger" is also harder to define, since the bullying occurs via technology, so the difference in "strength" is not easy to identify.

The idea that the bullying needs to be repeated many times is also more complicated when we think about cyberbullying. Generally, face-to-face bullying occurs repeatedly, at school or out of school. On the other hand, a cyberbullying act only needs to happen once, and then, it can be shared or brought back up over and over again, even days later. That means that a single cyberbullying post is enough to potentially create a large number of bullying incidents.

Another complicated aspect of cyberbullying is the idea of intent, which means hurting someone on purpose. Generally, in face-to-face bullying, the bully is purposefully trying to hurt the victim. Cyberbullying, however, can sometimes happen when the person doing the bullying may not realize how upsetting what he or she is doing actually is for the victim, or the bully may think that what he or she is doing is a joke. The problem here is that, even if the bully was joking around, the victim may be as upset about the incident as he would have been if the bully had been intentionally trying to upset him. So, you can see that including the intent to cause harm in the definition of cyberbullying is a complicated idea.

\section{WHY IS CYBERBULLYING SO BAD?}

Cyberbullying can have terrible consequences, whether the person is the victim or the bully, and researchers all over the world are trying to think of ways to help young people deal with cyberbullying. Some young people can get (or have worse) mental health problems because of cyberbullying, and sadly, a lot of young people do not ask for help 
when they are cyberbullied. Young people can often feel like no one will understand what they are going through or that nothing can be done to fix the cyberbullying. Young people might also be afraid that their parents will take their technology away or that their parents will come to the school and embarrass them. As a result, the victims of cyberbullying may start to isolate themselves and feel alone, and this can have drastic consequences for their overall wellbeing and mental health.

It can be hard to tell if someone is being cyberbullied if that person does not tell anyone. So, it is important for young people to look out for one another and keep an eye out for any changes in friends' behavior, such as no longer being interested in things they used to love or spending more and more time at home alone. This means that it is really important for young people to stay connected with their family, friends, and wider community, and reach out if they experience cyberbullying, because remaining socially connected can really help.

\section{WHAT IS SOCIAL CONNECTEDNESS?}

People feel socially connected when they feel comfortable, confident, and like they belong with not only their family and friends, but the community [2]. If people are struggling to feel socially connected, then they may feel unable to relate to the people around them, and they may struggle to make friends or to understand their role in the world, and feel all alone because of this [2]. Feeling all alone can then lead to a number of other problems, such as low self-esteem, not trusting other people, and just feeling lonely and as though they do not belong [2]. Imagine, what would happen if a person who is already feeling these things is also cyberbullied? Such a person might feel like there is no one to turn to.

Since everybody is different, people may feel this sense of connection and belonging in different ways. Some young people may feel really connected to their schools, whether it be through groups that they are a part of or because of particular teacher. Other young people may feel really connected to their parents and may confide in them easily. It is best when young people feel like they are connected in all aspects of their lives, beyond just their friends, families, and schools. In other words, young people should feel connected to their communities and to the world around them, possibly through sporting groups, community events, or online activities.

For young people, feeling socially connected does not always happen through seeing others face-to-face. Given how popular social media is today, there are hundreds of ways that young people can connect 
with other people without even seeing them. Young people can talk to each other through social media, apps on their phones, text messages, phone calls, video calls, and online gaming. Therefore, there are many ways that young people can talk to each other and feel connected when they perhaps do not feel like seeing people face-to-face.

Some researchers suggest that online social networking may provide the chance for young people to build a sense of connectedness online, and that this may help them to be happier and healthier and even more connected with others than they would be if they only had face-to-face communication [3]. However, it is important to remember that some people prefer to connect with others face-to-face, and not everyone feels connected to others when they go online. So, it is important to emphasize that feeling socially connected and feeling like you belong can happen through both online and offline methods that provide a sense of connection. Both online and offline types of connectedness are important.

\section{SOCIAL CONNECTEDNESS AND MENTAL HEALTH}

Adolescence can be a tough time for young people. Lots of things are happening and changing, and so this is a time when young people are most vulnerable to mental health issues. It is important for young people to stay connected with their friends and families during this time, so that they do not feel alone. Research has shown that people who are more socially connected are more likely to have positive mental health and wellbeing [4]. Therefore, it is important that young people are made aware of how important it is to be, whether that is online, offline, or both. Having someone to talk to when you are feeling down or alone is really important for positive mental health and wellbeing, and seeking help is the first step toward feeling better during those naturally difficult times.

So, while researchers already know that being socially connected is important for mental health, very little research has examined how

SOCIAL

CONNECTEDNESS

People feel socially connected when they feel comfortable, confident, and like they belong with not only their family and friends, but the community. important social connectedness is for people who are being cyberbullied and/or cyberbullying others.

\section{SOCIAL CONNECTEDNESS, CYBERBULLYING, AND TRADITIONAL BULLYING}

Only one study so far has looked at the relationship between social connectedness and cyberbullying [5]. This study found that cyberbullyvictims (people who have been both a cybervictim and a cyberbully) 
were significantly less socially connected than people who had never been a cybervictim or a cyberbully. The study also found that people who had only been cybervictims (but had not been cyberbullies) were also significantly less socially connected than people who had never been cybervictims. Although this is only one study and further research is needed, these results could mean that some young people who experience cyberbullying, whether as bullies or victims, feel less socially connected than do young people who have never been a victim or bully online. Whether this lack of connectedness causes the bullying or whether the bullying causes the lack of connection is still unclear. Either way, this research tells us that feeling connected to others and like they belong is very important for the mental health of young people.

Remember that, most of the time, people who experience cyberbullying have also experienced face-to-face bullying. People who are bullied offline are also likely to be less socially connected than people who are not experiencing bullying at all. Therefore, being connected both online and offline, and feeling a sense of identity and belonging from these connections, are important for everyone's positive mental health and wellbeing.

\section{WHAT DOES THIS ALL MEAN?}

To summarize what we have told you in this article, research shows that young people who are bullied (whether online or face-to-face) often have poor mental health, are lonely and disconnected, and may not seek help or support [5]. This means that being connected to the people around you is very important for your wellbeing, and asking for help is not a sign of weakness. Remaining connected to family, friends, and community will give you a better chance of remaining positive and will decrease the likelihood that you may suffer from poor mental health. It is important for all young people to understand how important it is to remain connected to others, especially if they are being cyberbullied. It is also important for parents, teachers, and schools to understand that some young people may feel very connected to the world around them when they are online, so taking technology away might not always be a solution to cyberbullying. It is possible that a young person's online connections might be the best way for that person to cope with cyberbullying. Remember that social connection is a very important aspect of remaining happy and healthy, and it can be a protective mechanism for anyone experiencing cyberbullying. 


\section{REFERENCES}

1. Smith, P. K., Mahdavi, J., Carvalho, M., Fisher, S., Russell, S., and Tippett, N. 2008. Cyberbullying: its nature and impact in secondary school pupils. J. Child Psychol. Psychiatry 49:376-85. doi: 10.1111/j.1469-7610.2007.01846.x

2. Lee, R. M., and Robbins, S. B. 1995. Measuring belongingness: the social connectedness and the social assurance scales. J. Counsel. Psychol. 42:232-41. doi: 10.1037/0022-0167.42.2.232

3. Grieve, R., and Kemp, N. 2015. Individual differences predicting social connectedness derived from facebook: some unexpected findings. Comput. Hum. Behav. 51:239-43. doi: 10.1016/j.chb.2015.04.034

4. Arabiat, D. H., Shaheen, A., Nassar, O., Saleh, M., and Mansour, A. 2018. Social and health determinants of adolescents' wellbeing in Jordan: implications for policy and practice. J. Pediatr. Nurs. 39:55-60. doi: 10.1016/j.pedn.2017.03.015

5. Spears, B. A., Taddeo, C. M., Daly, A. L., Stretton, A., and Karklins, L. T. 2015 Cyberbullying, help-seeking and mental health in young Australians: implications for public health. Int. J. Public Health 60:219-26. doi: 10.1007/s00038-014-0642-y

SUBMITTED: 16 April 2018; ACCEPTED: 14 September 2018; PUBLISHED ONLINE: 08 October 2018.

EDITED BY: Fulvio D'Acquisto, University of Roehampton, United Kingdom

CITATION: McLoughlin LT and Hermens DF (2018) Cyberbullying and Social Connectedness. Front. Young Minds 6:54. doi: 10.3389/frym.2018.00054

CONFLICT OF INTEREST STATEMENT: The authors declare that the research was conducted in the absence of any commercial or financial relationships that could be construed as a potential conflict of interest.

COPYRIGHT () 2018 McLoughlin and Hermens. This is an open-access article distributed under the terms of the Creative Commons Attribution License (CC BY). The use, distribution or reproduction in other forums is permitted, provided the original author(s) and the copyright owner(s) are credited and that the original publication in this journal is cited, in accordance with accepted academic practice. No use, distribution or reproduction is permitted which does not comply with these terms.

\section{YOUNG REVIEWER}

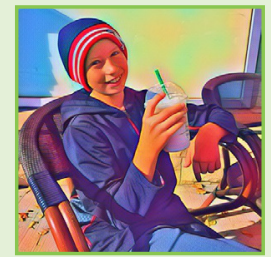

\section{BROCK, AGE: 12}

My interests include baseball, football, fishing, the outdoors, and reading. For the future, I am interested in becoming a conservationist or a scientist. I am particularly interested in trout and their habitats and the whirling disease that has impacted our Canadian lakes and rivers. I am an avid fisherman and am currently learning how to fly fish. I love science and I am very curious about the world around me. 


\section{AUTHORS}

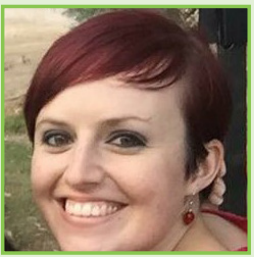

\section{LARISA T. MCLOUGHLIN}

I research cyberbullying and mental health in young people. My research has focused on the importance of social connectedness, and I am looking at how the brain responds to cyberbullying. I really hope to help young people lead healthier and happier lives. Fun fact about me: I am an identical twin. My twin sister is not a doctor like me but she is an iron woman! I like going to the gym and performing aerial arts when I'm not researching. *Imclough@ausc.edu.au

\section{DANIEL F. HERMENS}

I am a brain scientist and I study mental disorders, including ADHD, depression, and psychosis. My research has focused on adolescents and young adults, which I think is the most interesting and dynamic time of life in terms of brain changes. Currently, my favorite part of the brain is the hippocampus. When I'm not doing research, I like to gaze at architecture, go on long bike rides or dance "robot-style" with my two daughters while we listen to Daft Punk. 